DOI: $10.17951 /$ lrp. 2017.36.4.13

\author{
MARTA WroŃSKA
}

Uniwersytet Rzeszowski

\title{
TECHNOLOGIE INFORMACYJNE W EDUKACJI - STAN OBECNY I PERSPEKTYWY ICH ZASTOSOWANIA
}

\begin{abstract}
Streszczenie: Dynamiczny rozwój technologii cyfrowych wywiera coraz większy wpływ na wszystkie obszary naszego życia. Coraz trudniej znaleźć dziedziny, w których technologie cyfrowe nie mają zastosowania. Nowe technologie zmieniają także oblicze edukacji, która przestała być czymś danym raz na zawsze. Młodych ludzi szczególnie pociągają nowinki technologiczne. Zatem absurdem jest oczekiwanie, że kolejne pokolenia będą pozytywnie reagowały na wiedzę przekazywaną w tradycyjny sposób, skoro urodziły się i żyją w epoce mediów cyfrowych. Czy technologie informacyjne są uwzględnione w projekcie nowej podstawy programowej dla szkoły podstawowej i w jakim zakresie? Jest to istotne pytanie, ponieważ aktualnie mamy do czynienia $\mathrm{z}$ dynamicznym procesem przenoszenia aktywności młodego pokolenia do cyberprzestrzeni. Ważne jest, by uczniowie świadomie i konstruktywnie wykorzystywali najnowsze technologie informacyjne, a tego powinni uczyć się w szkole.
\end{abstract}

Słowa kluczowe: technologie informacyjne, edukacja, nowa podstawa programowa

\section{WPROWADZENIE}

Współcześnie życie społeczne, kulturowe, ekonomiczne czy polityczne jest związane nierozerwalnie z cyfrowymi technologiami, a także cyberprzestrzenią. Przygotowanie uczniów do funkcjonowania w coraz szybciej zmieniającej się w wyniku dynamicznego rozwoju technologii telekomunikacyjnych rzeczywistości nie jest łatwym zadaniem. Jak twierdzi Jerome Bruner, szkoła powinna być miejscem, w którym uczymy się, jak „używać umysłu, w jaki sposób odnosić się do autorytetów, jak traktować innych [...]. Edukacja jest ryzykowna, ponieważ wzbudza poczucie możliwości” (Bruner 2006, s. 69, 116) w różnych aspektach. Młodych ludzi szczególnie pociągają nowinki technologiczne. Zatem absurdem jest oczekiwanie, że kolejne pokolenia będą pozytywnie reagowały na wiedzę przekazywaną 
w tradycyjny sposób, skoro urodziły się i żyją w epoce mediów cyfrowych. Dobra szkoła ma dążyć do współdziałania czy zespolenia z przestrzenią medialną oraz w praktyczny sposób przygotowywać uczniów do życia w otaczającej ich rzeczywistości, a także przestrzegać przed zagrożeniami, jakie mogą napotkać. Aktualnie mamy do czynienia $\mathrm{z}$ dynamicznym procesem przenoszenia aktywności młodego pokolenia do cyberprzestrzeni, która daje im niespotykaną dotąd w dziejach ludzkości swobodę. A szkoła, do której uczęszczają, w ich opinii straciła sens: zmusza, a nie zachęca, to muzeum kredy i gąbki, gdzie owo pokolenie czuje się wyraźnie znudzone i chce szybko z niej uciec. Wie, że w komputerach podłączonych do sieci ma nieograniczoną możliwość poznawania tego, co je szczególnie interesuje. Cyfrowa przestrzeń niewątpliwie bezpośrednio i pośrednio modyfikuje edukację młodzieży, jej przebieg oraz osiągane efekty. Nastolatki otrzymują znacznie większą paletę możliwości w obecnym wielokulturowym, stechnicyzowanym świecie niż pokolenie ich rodziców i dziadków. Dotyczy to także rzeczywistości szkolnej, ale tego uczniowie nie dostrzegają, ponieważ ich "naturalnym środowiskiem” stała się przestrzeń medialna.

Obecnie w Polsce jesteśmy na etapie kolejnej reformy systemu szkolnego, która wprowadza ośmioletnią szkołę podstawową, czteroletnie liceum i pięcioletnie technikum oraz dwustopniowe szkoły branżowe. Zmiany mają rozpocząć się od roku szkolnego 2017/2018. Przeprowadzana reforma edukacji wywołuje liczne emocje wśród uczniów, rodziców i nauczycieli. Sam projekt nowej podstawy programowej (zob. Projekt rozporzadzenia Ministra Edukacji Narodowej w sprawie podstawy programowej wychowania przedszkolnego...) został oceniony przez ekspertów Komitetu Nauk Pedagogicznych Polskiej Akademii Nauk jako wytwór niskiej jakości, kolejna, nieudana niestety, wersja programu kształcenia będąca wyznacznikiem działalności szkoły (zob. Śliwerski 2017). Również wprowadzane zmiany w obszarze medialnym budzą niepokój.

\section{TECHNOLOGIE INFORMACYJNE - DWUTOROWOŚĆ ODDZIAŁYWAŃ}

Dynamiczny rozwój technologii cyfrowych wywiera coraz większy wpływ na wszystkie obszary naszego życia. Coraz trudniej znaleźć dziedziny, w których technologie cyfrowe nie mają zastosowania. Kiedy w latach 60. ubiegłego wieku rozpoczęto prace nad wykorzystaniem sieci komputerowej, nikt prócz garstki cyberentuzjastów nie przewidywał, że połączenie ze sobą kilku komputerów zrewolucjonizuje codzienne życie pokolenia przełomu wieków, zapoczątkuje gwałtowną ekspansję komunikacji za pośrednictwem komputera, która w ciągu dekady zdominuje globalną kulturę. Rozwój technologii cyfrowych stymuluje co- 
raz śmielsze wymagania użytkowników i odwrotnie - nowe wymagania i trendy determinują rozwój kolejnych technologii. Derrick de Kerckhove podkreśla, że „jeśli naprawdę chcemy poznać możliwości technologii cyfrowej i tkwiący w niej potencjał interaktywności, musimy dokonać fundamentalnej zmiany sposobu widzenia" (de Kerckhove 2001, s. 36). Według autora interaktywność oznacza, że odbiorca (użytkownik) nadaje treści kształt albo dzięki nielinearnemu dostępowi do niej, albo przez przejęcie pełnej odpowiedzialności za nią jako faktyczny dostawca treści. Wiadomość przesyłaną przez medium należy traktować jako sposób kształtowania odbiorcy przez nakłanianie go do kontaktu z tym medium (tamże). Jak pisze Didier Lombard, prezes jednej z największych europejskich spółek technologicznych France Telecom-Orange, współtwórca francuskich satelitów telekomunikacyjnych, standardu GSM:

Przeżywamy dziś głęboką przemianę technologiczną. Nie dotyczy ona wyłącznie elit - dotyka każdego z nas. Oczywiście niektórzy w to wątpią i mówią: $\mathrm{Z}$ nowymi technologiami jest zawsze tak samo: każdego dnia obiecują nam rewolucję nazajutrz. [...] W telekomunikacji co dzień pojawia się mnóstwo nowych kompetencji i idei. Część z nich znika równie szybko, jak się pojawiły. Towarzyszący im często entuzjazm rozmiłowanych w technologii osób może zarażać zewnętrznego obserwatora, zainteresowanego przede wszystkim - i słusznie - użytecznością i wygodą, możliwym do uzyskania dzięki tym innowacjom (Lombard 2009, s. 6).

W erze informacyjnej wyczuwa się na świecie pewne niezadowolenie z procesów wywołanych postępem technologicznym. Manuel Castells pisze o „cyfrowym podziale" społecznym wywołanym nierównym dostępem do sieci internetowej. Ale także formułuje pytania: czy na pewno ludzie i państwa są poza nawiasem, ponieważ nie mają dostępu do sieci opartych na Internecie, czy też właśnie włączenie ich do sieci uzależnia ich od gospodarek i kultur, w których mają niewielkie szanse znalezienia własnej ścieżki prowadzącej do materialnego dobrobytu i tożsamości kulturowej? pod jakimi warunkami i z jakich powodów włączenie lub nie do światowej sieci przekłada się na większe możliwości lub większe nierówności? (Castells 2003, s. 275). O negatywnych konsekwencjach stosowania technologii cyfrowych pisze m.in. Steven Jones - profesor Uniwersytetu Illinois w Chicago, który dokonał konceptualizacji problematyki powstawania społeczności wirtualnych oraz zwrócił uwagę na negatywne zjawiska towarzyszące budowaniu tych społeczności, charakteryzując społeczności niszowe oparte na ideach nietolerancji (zob. Jones 1998, s. 1-35).

Można zatem mówić o dwutorowości oddziaływań technologii cyfrowych pozytywy i negatywy zazębiają się. Chwilami zaczyna się wydawać, że technologie 
niszczą to, co tworzą. Co zatem zrobić, by technologie cyfrowe nie zdominowały nas całkowicie? Technologie cyfrowe wytwarzają różnego rodzaju dylematy natury społecznej bądź etycznej. Jednak w porównaniu do poprzedniej generacji techniki tych dylematów jest więcej i mają inny charakter. Jak twierdzą Kazimierz Krzysztofek i Marek Szczepański, technologie te rodzą konflikty między: zasadami demokracji społecznej i ekonomicznej a wymogami rynku w dziedzinie komunikacji; interesami operatorów sieci i ich właścicielami a ogólnymi interesami użytkowników; uniwersalnością narzędzia, którym potencjalnie mogą dysponować wszyscy, a niebezpieczeństwem ekonomicznego, politycznego i kulturowego wykluczenia wielkich grup; potrzebami w zakresie bezpieczeństwa i kontrolowania sieci a suwerennością jednostki, jej prawem do prywatności; zawartością programów produkowanych przez podmioty działające na rynku a realnymi potrzebami społeczeństw; bogactwem wirtualnej komunikacji a izolacją jednostki sam na sam z komputerem; użyciem nowych technologii dla rozwoju osobistego a ryzykiem manipulacji trudnej do zidentyfikowania; bezmiarem informacyjnej masy a praktyczną niemożliwością znalezienia czasu na zastanowienie pozwalające widzieć rzeczy we właściwej perspektywie (Krzysztofek, Szczepański 2002, s. 235). Umberto Eco konstatuje, że nowe technologie wprowadzają nowe formy uczenia się, rozumowania czy komunikowania. Świat intelektualny, zamiast przyjrzeć się kompetentnie i chłodno nowym mediom, ulega fascynacji dyskusjami „toczącymi się w tonie apokaliptycznym"1. Pozytywny jest natomiast fakt, że pojawienie się nowego środka przekazu nie tylko nie zabija poprzedniego, ale zawsze uwalnia go od takich czy innych serwitutów.

Technologie informacyjne stały się immanentną częścią życia współczesnego społeczeństwa. Przeniknęły do sfery zawodowej, gospodarczej, politycznej, zajmując w nich kluczową pozycję. Nowe technologie zmieniają oblicze edukacji, która przestała być czymś danym raz na zawsze. Musi być nieustannie uaktualniana. Warto zastanowić się, czy w procesie edukacji nowe technologie, $\mathrm{w}$ tym przede wszystkim mobilne, które uczniowie mają zawsze przy sobie, to naprawdę fanaberia młodzieży, moda i zbędny detal. Arthur Charles Clarke, angielski pisarz fantastycznonaukowy, propagator kosmonautyki, idealnie skonstatował: „Nie ma innego sposobu na odkrycie granic niemożliwego, jak wykroczyć poza nie w strefę niemożliwości" (Clarke 2000, s. 24).

${ }^{1}$ Fragmenty wykładu wygłoszonego przez Umberta Eco podczas wizyty w Polsce w 1996 r., opublikowano: http://www.plusgsm.pl/magazyn/99_18/czy.shtml [dostęp: 21.03.2016]. 


\section{TECHNOLOGIE INFORMACYJNE - ASPEKT EDUKACYJNY}

Obecnie ważne jest zbliżenie edukacji do rzeczywistości, której istnienie bez cyfrowych mediów jest już niemożliwe. Ken Robinson, lider w dziedzinie rozwoju kreatywności, innowacyjności i potencjału ludzkiego, trafnie zauważa, że:

[...] przy wyzwaniach, przed jakimi stoimy, edukacja nie musi przechodzić reformy - musi przejść transformację. Kluczem do tej transformacji nie jest standaryzacja edukacji, ale jej personalizacja, budowanie osiągnięć na odkrywaniu indywidualnych talentów każdego dziecka, umieszczanie uczniów w środowisku, w którym chcą się uczyć i w którym mogą naturalnie odkrywać swoje pasje (Robinson, Aronica 2012, s. 198).

W procesach edukacyjnych bardzo przydatne są technologie cyfrowe, czyli urządzenia wykorzystywane do zbierania, przechowywania, przetwarzania i przesyłania informacji oraz skuteczne metody wykorzystania tych urządzeń. Dużo młodych osób jest zafascynowanych tymi technologiami, fascynacja niekiedy graniczy z fanatyzmem oraz uzależnieniem, które prowadzi do immersji. Doświadczenie immersji uzależnione jest na dodatek od kontekstu odbiorczego, konwencji i stopnia, w jakim odbiorcy zaznajomieni są z medium będącym nośnikiem immersyjności (Krueger 1991, s. 84-85). Technologie cyfrowe nadają zjawisku immersyjności nowego wymiaru, wzbogacając je o wielokanałowe strumienie sygnałów, responsywność i dostarczaną przez coraz to doskonalszą technologię teleobecność i jej różne odmiany. Technologie cyfrowe kształtują użytkowników, ale też użytkownicy mają pewien zakres swobody, w ramach której kształtują technologie od nowa, niezależnie od założeń i postulatów ich twórców. Zjawiska te sugerują, że technologii cyfrowych nie należy bagatelizować. Są one jedną z wielu zmiennych powiązanych z efektywnością nauczania w szkole.

Zadaniem nauczyciela jest pokazywanie, akcentowanie, eksponowanie zalet i wad nieograniczoności technologii informacyjnych. Na pewno korzystne dla uczniów będzie dążenie przez nauczyciela w stronę edukacji hybrydowej, czyli łączenia tradycyjnych lekcji z zajęciami w przestrzeni wirtualnej. Przydatna może być także gamifikacja, gdzie nauka odbywa się głównie przez gry. Zamiast uczestniczyć w tradycyjnych lekcjach uczniowie podejmują fikcyjne wyzwania, wyruszają na misje, podczas których poszukują rozwiązania złożonych problemów. Na końcu czeka ich ostateczna potyczka (boss fight), w której by stawić czoła wyjątkowo trudnemu zadaniu, muszą wykorzystać zdobytą wcześniej wiedzę i doświadczenie. Gry dają poczucie satysfakcji nawet przy najmniejszym sukcesie. Eliminują psychologiczne skutki porażki na rzecz wiedzy. Można także wykorzystać popu- 
larną w Stanach Zjednoczonych ideę flipped classroom (odwrócona klasa), której istotą jest to, że na przebieg i treść lekcji wpływają pytania uczniów motywowane próbą opracowania nowego materiału (Springen 2013, s. 22-26). To tylko wybrane przeze mnie przykłady zmian w obecnej szkole, które mogą zwiększyć aktywność uczniów i ich motywację do nauki i pracy nad samym sobą.

Obowiązek związany z podjęciem nowych wyzwań edukacyjnych spoczywa właśnie na nauczycielu, który sam musi się nauczyć skutecznie działać w szybko zmieniającej się rzeczywistości oraz posiadać wysokie kompetencje medialne. Znaczenie i obecność nauczyciela w procesach edukacyjnych docenia Władysław P. Zaczyński, podkreślając, iż

nauczyciel jest potrzebny nie tylko po to, by wskazywać uczniom informacje ważne lub „uczyć" ich czynienia właściwego użytku z informacji internetowej, ale nadto po to, by przez swą fizyczną bliskość i emocjonalne więzi z uczniami uwiarygodnić wybraną informację i nadto, by pozytywnie motywować do poszukiwania informacji ważnych (Zaczyński 2001, s. 237).

Obecność nauczyciela w szkole potrzebna jest też po to, by nie dochodziło do takich sytuacji, jakie opisuje Neil Postman, że młodzi ludzie w wyniku niskiej samowiedzy o edukacji technologicznej nie używają technologii, ale są przez nią „używani”.

Tradycyjny nauczyciel, który tylko transmituje wiadomości, zadaje prace domowe, czyli stosuje zasadę najmniejszego wysiłku (least-effort principle), a gdy nie wie, jak coś osiągnąć - dyscyplinuje, każe, wymusza, zastrasza, nie będzie nauczycielem efektywnym, a jego skuteczność i powodzenie wśród uczniów będzie znikome. W nowoczesnym podejściu do edukacji nauczyciel ma być doradcą ucznia w zdobywaniu umiejętności, facylitatorem, przewodnikiem po coraz bardziej skomplikowanych, często hipermedialnych strukturach informacyjnych. Im prędzej nauczyciele to odkryją, tym szybciej zyskają i zwiększą swój autorytet u uczniów. Nauczyciele aktywni zawodowo są świadomi, że muszą być kompetentni w obszarze wykorzystywania technologii informacyjnych. W praktyce wygląda to nieco inaczej. Szczegółowa analiza uzyskanego przeze mnie materiału badawczego (zob. Wrońska 2012), obejmującego obszar wiadomości o mediach, umiejętności ich stosowania i postaw wobec mediów nauczycieli i adolescentów, ewidentnie wykazała dysonans $\mathrm{w}$ działaniach medialnych nauczyciela i ucznia. Poziom wiedzy o współczesnych mediach elektronicznych oraz poziom wiedzy proceduralnej, czyli wiedzy typu „wiem jak”, badanych nauczycieli został określony w skali pięciostopniowej jako przeciętny i jest zdecydowanie niższy niż poziom tej wiedzy wśród uczniów. Przy ustalaniu poziomów uwzględniono wymagania 
i oczekiwania wobec aspektów medialnych sformułowanych w obowiązującej podstawie programowej (zob. Rozporzadzenie Ministra Edukacji Narodowej z dnia 27 sierpnia $2012 r$. w sprawie podstawy programowej wychowania przedszkolnego oraz kształcenia ogólnego $w$ poszczególnych typach szkól). Niski poziom wiedzy o mediach oraz umiejętności stosowania mediów sprawia, że badani nauczyciele prezentowali postawy wobec mediów, które scharakteryzować można jako negatywne, a w wielu przypadkach jako zdecydowanie negatywne. Wyniki te pokazały, że nauczyciele, którzy mają medialnie edukować uczniów, posiadają w porównaniu do wychowanków spore braki.

\section{TECHNOLOGIE INFORMACYJNE W PROJEKCIE NOWEJ PODSTAWY PROGRAMOWEJ}

Projekt nowej podstawy programowej dotyczy tylko szkoły podstawowej. W projekcie znajduje się zapis:

Szkoła podstawowa przygotowuje uczniów do świadomego i odpowiedzialnego korzystania z technologii informacyjno-komunikacyjnych. Wyposaża ich w kompetencje potrzebne do korzystania z różnych cyfrowych zasobów informacyjnych, wyszukiwania i krytycznej analizy informacji, bezpiecznego poruszania się w przestrzeni cyfrowej, w tym nawiązywania i utrzymywania opartych na wzajemnym szacunku relacji z innymi użytkownikami sieci (Rozporzadzenie Ministra Edukacji Narodowej z dnia 27 sierpnia $2012 \mathrm{r}$. w sprawie podstawy programowej wychowania przedszkolnego oraz kształcenia ogólnego w poszczególnych typach szkót).

W tak sformułowanym zapisie pojęcie, które jest obecne w obowiązującej nadal podstawie programowej: „każdy nauczyciel”, zostało zastąpione przez „szkołę”, czyli nauczyciel bezpośrednio został zwolniony z obowiązku edukacji medialnej uczniów, odpowiedzialność spadła na całą szkołę. Wiemy dobrze, co oznacza zbiorowa odpowiedzialność.

W przedstawionym do konsultacji projekcie technologie informacyjne są obecne tylko w edukacji informatycznej, która nie jest tożsama z edukacją medialną. Już na pierwszym etapie nauczania w klasach I-III zostaje wprowadzona edukacja informatyczna zakładająca osiągnięcia w zakresie przygotowania do programowania oraz osiągnięcia w zakresie pracy z urządzeniami. Niepokoi mnie sformułowanie, określone w osiągnięciach w zakresie pracy z urządzeniami, że uczeń „ma świadomość istnienia różnorodnego oprogramowania i dostosowania jego funkcji do rodzaju wykonywanych zadań". Czy aby sama świadomość wystarczy, by dobrze 
funkcjonować w przestrzeni medialnej? Pozostaje tylko nadzieja, że zajęcia $\mathrm{z}$ informatyki realizowane w szkole podstawowej przygotują uczniów do konstruktywnego posługiwania się mediami i wykorzystywania ich w rozwoju intelektualnym i zawodowym. Wpłyną na kształtowanie i doskonalenie umiejętności świadomego, refleksyjnego i krytycznego odbioru przekazów medialnych oraz ocenianie, wartościowanie i projektowanie różnorodnych komunikatów multimedialnych, takich jak np. strony internetowe, materiały filmowe, prezentacje itp. Ważne jest sprawne i skuteczne posługiwanie się smartfonem, iPhonem, tabletem, aparatem fotograficznym, mikrofonem, kamerą wideo, a także narzędziowymi programami komputerowymi, skanerem itp. Uczniowie muszą też wiedzieć, jakie mechanizmy oddziaływania na odbiorców stosują autorzy komunikatów medialnych. Istotna jest także umiejętność pozyskiwania, przetwarzania, weryfikowania i przekazywania informacji, a to było istotą edukacji medialnej, która została wycofana $\mathrm{z}$ obowiązującej podstawy programowej i również pozostaje nieuwzględniona w projekcie.

\section{PODSUMOWANIE}

Współczesna szkoła ma być skuteczna, efektywna, przyjazna i nowoczesna. Obecne powinny w niej być technologie informacyjne, które sprzyjają uczeniu się polisensorycznemu. Kształcą wiele cennych umiejętności, uczą np. samodzielności w planowaniu i wykonywaniu zadania lub współdziałania w grupie. Jednak na podstawie samego używania nowych technologii w danej szkole nie można mówić o innowacyjności prowadzanych zajęć przez nauczycieli. Należy zmienić samą metodykę nauczania. Maureen Baron zaznacza, że dzisiaj, by nie być osobą określaną jako analfabeta, konieczne jest posiadanie zdolności dekodowania, rozumienia, oceniania i pisania za pomocą różnych form medialnych oraz czytania, oceniania i tworzenia tekstów, obrazów i dźwięków, a także różnych kombinacji tych elementów. Autorka dodaje, że osoba wykształcona musi z definicji opanować komunikowanie się za pomocą pisma oraz mediów, a także nie może być analfabetą medialnym i technologicznym (Baron 2004). Szkoły powinny sprzyjać rozwojowi uczniów potrafiących krytycznie postrzegać, analizować i interpretować otaczającą ich rzeczywistość z konstruktywnym wykorzystaniem technologii informacyjnych. Nie da się już budować nauki tylko na tradycji, z dala od nowoczesności. 


\section{LITERATURA}

Baron M., 2004, Literacy, Then and Now, za: Dylak S., 2004, Kompetencje medialne jako ważny nurt w edukacji humanistycznej. W: Strykowski W., Skrzydlewski W. (red.), Kompetencje medialne społeczeństwa wiedzy. Poznań, Wydawnictwo eMPi2. Bruner J., 2006, Kultura edukacji. Kraków, Wydawnictwo Universitas.

Castells M., 2003, Galaktyka Internetu. Refleksje nad Internetem, biznesem i społeczeństwem, Poznań, Wydawnictwo Nowe Horyzonty.

Clarke A. C., 2000, Profiles of the Future: An Inquiry into the Limits of the Possible. London, Wydawnictwo Orion Publishing.

Jones S., 1998, Information, Internet and Community: Notes Toward an Understanding of Community in the Information Age. W: S. Jones (red.), Cybersociety 2.0, Revisiting Computer-Mediated Communication and Community. Sage Publications, Thousand Oaks, CA.

Kerckhove de D., 2001, Inteligencja otwarta. Narodziny społeczeństwa sieciowego. Warszawa, Wydawnictwo Mikom.

Krueger M. W., 1991, Artificial Reality II. London, Addison-Wesley Reading, MA.

Krzysztofek K., Szczepański M., 2002, Zrozumieć rozwój. Od społeczeństw tradycyjnych do informacyjnych. Katowice, Wydawnictwo UŚ.

Lombard D., 2009, Globalna wioska cyfrowa, drugie życie w sieci. Warszawa, Wydawnictwo MT Biznes.

Projekt rozporzadzenia Ministra Edukacji Narodowej w sprawie podstawy programowej wychowania przedszkolnego oraz podstawy programowej kształcenia ogólnego dla szkoły podstawowej, w tym dla uczniów z niepełnosprawnościa intelektualna w stopniu umiarkowanym lub znacznym, kształcenia ogólnego dla branżowej szkoły I stopnia, kształcenia ogólnego dla szkoły specjalnej przysposabiającej do pracy oraz kształcenia ogólnego dla szkoły policealnej, załącznik nr 2, opublikowano: http://legislacja.rcl.gov.pl/projekt/12293659/katalog/12403169\#12403169 [dostęp: 24.10.2016].

Robinson K., Aronica L., 2012, Uchwycić żywioł. O tym, jak znalezienie pasji zmienia wszystko. Kraków.

Rozporzadzenie Ministra Edukacji Narodowej z dnia 27 sierpnia 2012 r. w sprawie podstawy programowej wychowania przedszkolnego oraz kształcenia ogólnego w poszczególnych typach szkół (Dz.U. 2012, poz. 997).

Springen K., 2013, Flipping the Classroom: a Revolutionary Approach to Earning Presents Pros and Cons for Educators. "School Library Journal", no 4, vol. 59.

Śliwerski B., 2017, Bubel programowy MEN w opinii ekspertów KNP PAN, opublikowano: http://sliwerski-pedagog.blogspot.com/2017_01_01_archive.html [dostęp: 08.02.2017]. 
Wrońska M., 2012, Kultura medialna adolescentów. Studium dostępu i zastosowań. Rzeszów, Wydawnictwo Uniwersytetu Rzeszowskiego.

Zaczyński W. P., 2001, Nauczanie z komputerem w kontekście sporu o wartość nauki. W: J. Morbitzer (red.), Techniki komputerowe w przekazie edukacyjnym. Kraków, Wydawnictwo AP.

\title{
INFORMATION TECHNOLOGIES IN EDUCATION - CURRENT SITUATION AND PROSPECTS OF APPLICATION
}

\begin{abstract}
Dynamic development of digital technologies has been increasingly influencing all areas of our life. It is more and more difficult to find disciplines in which digital technologies have no application. New technologies have been also changing the face of education which has ceased to be something definite. Young people are especially attracted to latest technological developments. Therefore, it is absurd to expect that next young generations will have positive attitude towards knowledge presented in a traditional way as they were born and have been living in the era of digital media. Are information technologies present in the project of a new core curriculum for primary school and to what extent? It is a crucial question because at present we deal with a dynamic process of transferring the young generation activity to the cyberspace. It is vital that pupils use the latest information technologies consciously and constructively and this is something they should be taught at school.
\end{abstract}

Keywords: information technology, education, the new core curriculum 